\section{New Data Set of Onset of Annual Snowmelt on Antarctic Sea Ice}

\section{PAGES 237,241}

The annual onset of snowmelt on sea ice is essential for climate monitoring since it triggers a decrease in surface albedo that feeds back into a stronger absorption of shortwave radiation-a process known as the snowmelt-albedo feedback - and thus strongly modifies the surface energy balance during summer [Curry et al., 1995]. Algorithms designed for the detection of snowmelt on Arctic sea ice and based on longterm passive-microwave data [Anderson, 1997; Drobot and Anderson, 2001] revealed the melt season in the Arctic from 1979 to 1998 to be significantly elongated and the onset of melt to be shifted toward earlier dates [Drobot and Anderson, 2001; Belchansky et al., 2004].

In the Antarctic, however, little effort has been made so far in detecting the length of the summer melt season on sea ice by means of satellite microwave data. This results from the fact that surface melting in the Antarctic differs significantly from corresponding processes in the Arctic [Nicolaus et al., 2006]. The hemispheric differences are supported by extensive field measurements [Massom et al., 2001; Haas et al., 2001] and find expression in a reversal of the general surface radar backscatter and brightness temperature $\left(T_{B}\right)$ tendencies during summer [Haas, 2001; Kern and Heygster, 2001]: In the Antarctic, sea ice backscatter increases and $T_{B}$ decreases when summer approaches, contrary to the Arctic. Hence, algorithms developed for Arctic sea ice are not applicable on its southern counterpart. As summer air temperatures in the Antarctic rarely rise above $0^{\circ} \mathrm{C}$, classical surface melt ponds have never been observed to the extent they appear in the Arctic and the sea ice surface typically remains snow-covered year-round. Drinkwater and Liu [2000] investigate snowmelt on Antarctic sea ice based on a method that identifies a decrease in surface radar backscatter. However, they detect melt to be lasting for only some days and exclusively on first-year ice. Presumably, the backscatter decrease they observe is due to flooding of the snow before the ice underneath finally deteriorates.

Consequently, a long-term observation of summer melt patterns over the entire sea ice area in the Antarctic demands criteria different from those used in the Arctic.

This article outlines a new method for the detection of snowmelt onset on Antarctic sea ice, derived from field measurements and long-term satellite data.

\section{Data Basis}

During the austral summer of 2004-2005, the Ice Station Polarstern (ISPOL) expedition [Hellmer et al., 2006] collected in situ data of sea ice and snow properties during the transition from spring to summer while temporal changes of passive and active microwave signals from satellite observations in the respective region were coincidently observed.

The main activity of ISPOL was the performance of a drift station in the western Weddell Sea from 28 November 2004 to 2 January 2005. During this time, the R/V Polarstern was anchored to an ice floe of consolidated firstand second-year ice patches. This allowed continuous measurements of properties of snow and ice and meteorological conditions. Our observations revealed the absence of strong and enduring meltwater formation in the snow. Instead, the measurements indicated that diurnal freeze-thaw cycles are the dominant process in generating the typical decrease of microwave $T_{B}$ and the increase of radar backscatter on

Antarctic sea ice during the summer [Willmes et al., 2007]. When the energy input to the surface strengthens, meltwater forms in the snowpack during the day, causing a rise of $T_{B}$. Yet as the snow refreezes at night, $T_{B}$ decreases again. This circumstance makes daily averages of $T_{B}$ incapable of indicating the temporally limited snowmelt.

Recapitulating our in situ measurements together with extensive analysis of satellite data, we suggest here that the summer melt period on Antarctic sea ice be defined through enhanced diurnal variability in snow wetness and thus emissivity and $T_{B}$. Thereby, the onset of summer melt can be identified from microwave data that provide at least twice-daily observations of the sea ice surface.

We used Special Sensor Microwave/Imager (SSM/I) swath data in combination with the ISPOL field data to investigate the potential of satellite data for the long-term observation of melt dynamics on Antarctic sea ice. Results show the summer period to be clearly silhouetted against the seasonal cycle of diurnal $T_{B}$ (Figure 1). Hence, we consider the diurnal $T_{B}$ variability a reliable indicator for melt processes within the snowpack on Antarctic sea ice while the evolution of daily averages of $T_{B}$ and radar backscatter is strongly biased by snow depth, the level of snow metamorphism, and ice type.

\section{Melt Detection Algorithm and Data Product}

On the basis of our findings, we developed a simple algorithm (Melt Detection Algorithm; MeDeA) to identify the onset of the annual summer melt period on Antarctic sea ice. MeDeA detects the first date with the 5-day average of the diurnal $T_{B}$ amplitude exceeding a threshold of $10 \mathrm{~K}$ for at least 3 consecutive days in the period from 1 October to 31 March. The threshold and the moving-window sizes were chosen after careful examination of ground truth data and coincident satellite observations. However, as the significance of freeze-thaw cycle strengthening during summer shows large spatial variations, a threshold adjustment to, for example, $12.5 \mathrm{~K}$ decreases the total amount of detected melt flags by approximately $20 \%$. This affects mostly sea ice in the marginal ice zone, where diurnal amplitudes of $T_{B}$ increase early, but are not very strong throughout each summer. For the remaining ice cover, moderate variations of thresholding and interdiurnal averaging caused only minor changes of the results presented in Figure 2.

We force the algorithm with twice-daily surface $T_{B}$ from the SSM/I pathfinder data set, which provides microwave $T_{B}$ data from 1987 to the present. Twenty years of summer $T_{B}$ were processed and combined in a comprehensive data set called Melt Detection on Antarctic Sea Ice (MEDAntS). The MEDAntS product includes (1) the annual date of snowmelt onset (Figure 2), (2) the annual date of freeze onset, (3) the duration of summer melt, and (4) the daily strength of the diurnal $T_{B}$ cycle from 1 October to 31 March for the entire area of Antarctic sea ice from 1987 to 2007 . The duration of summer melt can only be mapped for areas of perennial ice because most often ice breakup occurs earlier than the defined onset of steady freezing.

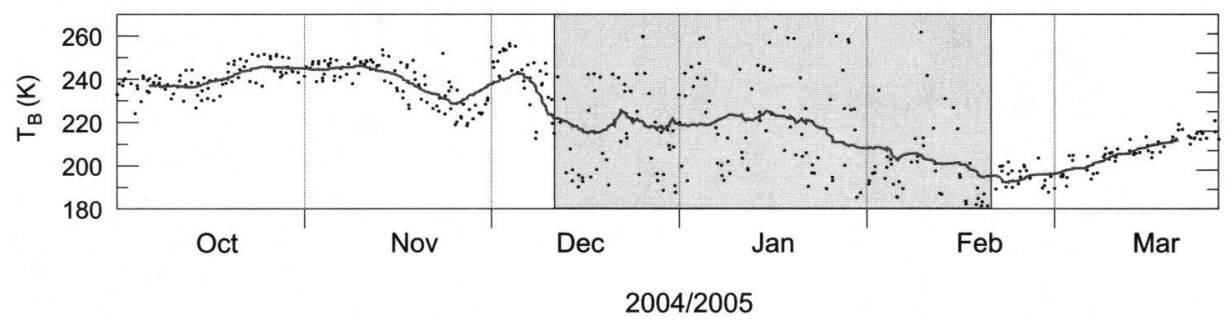

Fig. 1. Evolution of surface brightness temperature (37 gigahertz, vertical polarization) from Special Sensor Microwave/Imager (SSM/I) swath data (black dots) and moving average ( $n=31$, grey line) in the western Weddell Sea $\left(67.8^{\circ} \mathrm{S}, 55.4^{\circ} \mathrm{W}\right)$, October 2004 to March 2005. The identified melt season is highlighted by the shaded box. 
Melt-onset detection provides encouraging results. For example, MeDeA detects snowmelt to emerge later at higher latitudes and earliest at the marginal ice zone of the Weddell Sea (Figure 2) in the austral summer of 2004-2005, whereas in the western Pacific and Indian ocean sectors snowmelt occurs exclusively in coastal areas where sea ice does not retreat too fast for significant melt processes to take place.

The new algorithm can be used to map interannual variations in summer melt characteristics throughout each austral summer. There is considerable opportunity to use this new melt data set for climate studies, including the development and validation of general circulation model outputs, as well as for the detection of climate change signals.

This new product is now available online at the Web site of the Department of Environmental Meteorology at the University of Trier (http://klima.uni-trier.de).

\section{References}

Anderson, M. (1997), Determination of melt-onset date for Arctic sea-ice regions using passivemicrowave data, Ann. Glaciol. 25, 382-388.

Belchansky, G. I., D. C. Douglas, I. N. Mordvintsev, and N. G. Platonov (2004), Estimating the time of melt onset and freeze onset over Arctic sea-ice area using active and passive microwave data, Remote Sens. Environ., 92,21-39
Eos, Vol. 88, No. 22, 29 May 2007

Curry, J.A., J. L. Schramn, and E. E. Ebert (1995), On the ice albedo climate feedback mechanism, $J$. Clim., 9,240-247.

Drinkwater, M. R., and X. Liu (2000), Seasonal to interannual variability in Antarctic sea-ice surface melt, IEEE Trans. Geosci. Remote Sens., 38(4), 1827-1842.

Drobot, S. D., and M.R.Anderson (2001), An improved method for determining snowmelt onset dates over Arctic sea ice using scanning multichannel microwave radiometer and Special Sensor Microwave/Imager data,J. Geophys. Res. 106(D20), 24,033-24,049.

Haas, C. (2001), The seasonal cycle of ERS scatterometer signatures over perennial Antarctic sea ice and associated surface ice properties and processes, Ann. Glaciol., 33,69-73.

Haas, C., D. N. Thomas, and J. Bareiss (2001), Surface properties and processes of perennial Antarctic sea ice in summer,J. Glaciol., 47(159), 613-625.

Hellmer,H.H. C. Haas, G.S. Dieckmann, and M. Schröder (2006), Sea ice feedbacks observed in western Weddell Sea, Eos Trans. AGU, 87(18), $173,179$.

Kern, S., and G. Heygster (2001), Sea-ice concentration retrieval in the Antarctic based on the SSM/l $85.5 \mathrm{GHz}$ polarization, Ann. Glaciol., 33, 109-114.

Massom, R.A., et al. (2001), Snow on Antarctic sea ice, Rev. Geophys., 39(3), 413-445.

Nicolaus, M., C. Haas, S.Willmes, and J. Bareiss (2006), Differences of snow melting on Arctic and Antarctic sea ice during spring and summer,Ann. Glaciol., $44,147-153$

Willmes, S., J. Bareiss, C. Haas, and M. Nicolaus (2007), The importance of diurnal processes for the seasonal cycle of sea-ice microwave brightness temperatures during summer in the Weddell Sea, Ann. Glaciol., 44, 297-302.

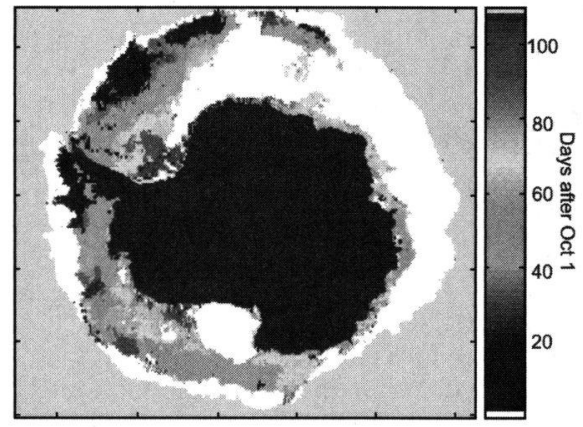

Fig. 2. Summer 2004-2005: spatial variability of the onset of summer melt on Antarctic sea ice (number of days after 1 October 2004). Melt is only identified for areas with sea ice concentrations higher than 15\%. No melt was detected on sea ice areas in white. Original color image appears at the back of this volume.

\section{Author Information}

Sascha Willmes, Department of Environmental Meteorology, University of Trier, Trier, Germany, EMail: willmes@uni-trier.de; Jörg Bareiss, Department of Environmental Meteorology, University of Trier; and Christian Haas, Alfred-Wegener-Institute for Polar and Marine Research, Bremerhaven, Germany. 